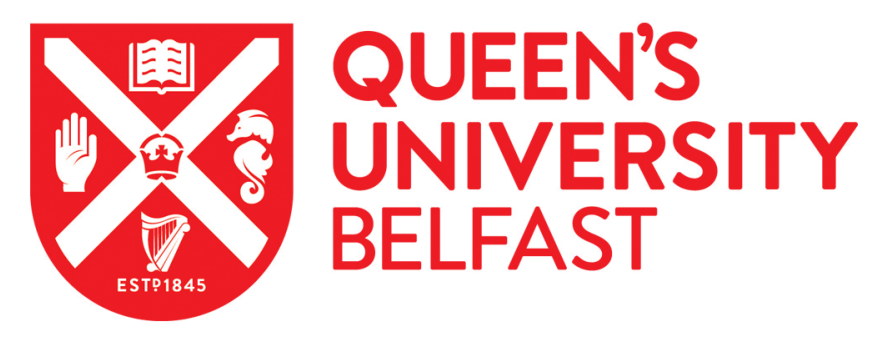

\title{
Correlation between the photocatalysed oxidation of methylene blue in solution and the reduction of resazurin in a photocatalyst activity indicator ink (Rz Paii)
}

Mills, A., Wells, N., \& O'Rourke, C. (2016). Correlation between the photocatalysed oxidation of methylene blue in solution and the reduction of resazurin in a photocatalyst activity indicator ink (Rz Paii). Journal of Photochemistry and Photobiology A: Chemistry, 330, 86-89. https://doi.org/10.1016/j.jphotochem.2016.07.020

Published in:

Journal of Photochemistry and Photobiology A: Chemistry

\section{Document Version:}

Peer reviewed version

Queen's University Belfast - Research Portal:

Link to publication record in Queen's University Belfast Research Portal

\author{
Publisher rights \\ (C) 2016 Elsevier B. V. This manuscript version is made available under the CC-BY-NC-ND 4.0 license \\ http://creativecommons.org/licenses/by-nc-nd/4.0/which permits distribution and reproduction for non-commercial purposes, provided the \\ author and source are cited.
}

\section{General rights}

Copyright for the publications made accessible via the Queen's University Belfast Research Portal is retained by the author(s) and / or other copyright owners and it is a condition of accessing these publications that users recognise and abide by the legal requirements associated with these rights.

Take down policy

The Research Portal is Queen's institutional repository that provides access to Queen's research output. Every effort has been made to ensure that content in the Research Portal does not infringe any person's rights, or applicable UK laws. If you discover content in the Research Portal that you believe breaches copyright or violates any law, please contact openaccess@qub.ac.uk. 


\title{
Correlation between the photocatalysed oxidation of methylene blue in solution and the reduction of resazurin in a photocatalyst activity indicator ink (Rz Paii)
}

\author{
Andrew Mills*, Nathan Wells, Christopher O’Rourke \\ Queen's University of Belfast, School of Chemistry and Chemical Engineering \\ e-mail: andrew.mills@qub.ac.uk
}

\begin{abstract}
The initial rate of the photocatalysed oxidation of methylene blue, $M B$, by dissolved oxygen in solution, $r_{i}(M B)$, is measured for a series of titania on glass samples exhibiting a wide range of activities. The samples used include two different types of commercial self-cleaning glass and a lab-made sol-gel titania film. The activities of these samples are also assessed using a resazurinbased photocatalyst activity indicator ink, i.e. Rz paii, for which the initial rates of the photocatalysed reduction of Rz were measured, $r_{i}(R z)$. A plot of $r_{i}(M B)$ vs. $r_{i}(R z)$ reveals a good straight line, thereby demonstrating a linear correlation (for $\mathrm{TiO}_{2}$ films on glass at least) between the slow (usually hours) photocatalysed oxidation of organic materials, such as MB, and the fast (typically minutes) photocatalysed irreversible reduction of a dye, like Rz, in a paii. The possible use of paii technology for assessing, in a simple, quick and inexpensive manner, photocatalytic films both in the laboratory and in situ is discussed briefly.
\end{abstract}

Key words: methylene blue; oxidation; resazurin; reduction; inks; correlation 


\section{Introduction}

Semiconductor photocatalysis is a well-established and growing area of research, innovation and commercialisation [1]; major examples of the latter include most 'self-cleaning' architectural materials, such as: glass, tiles, concrete, paint and fabrics [1,2]. In almost all such commercial products the active ingredient is $\mathrm{TiO}_{2}$, which absorbs UV light, from a solar and/or artificial light source, to produce electron-hole pairs, which can recombine, in the bulk of the semiconductor or, at its surface, recombine or react with surface-adsorbed species [3]. Most commercial photocatalytic materials use the $\mathrm{TiO}_{2}$ to mediate the photo-oxidation of adsorbed, usually organic, species to their mineral form, with the concomitant reduction of adsorbed $\mathrm{O}_{2}$ to water, i.e.

$$
\text { Organic }+\mathrm{O}_{2} \longrightarrow \mathrm{CO}_{2}+\mathrm{TiO}_{2} \mathrm{O}+\text { mineral acids }
$$

where mineral acids are generated if the organic species has one or more heteroatoms, such as $\mathrm{S}, \mathrm{Cl}$ or $\mathrm{N}$, in its structure [1]. The ability of $\mathrm{TiO}_{2}$ to photocatalyse reaction (1) is the primary photocatalytic property responsible for the promoted ability of commercial photocatalytic products to maintain a clean, sterile, hydrophilic surface [1,2]. Other work shows that $\mathrm{TiO}_{2}$ is also able to mediate the photo-oxidation of $\mathrm{NO}_{\mathrm{x}}$, i.e. $\mathrm{NO}$ and $\mathrm{NO}_{2}$, to nitrate [4].

In the ever-expanding field of photocatalysis it is essential to be able to assess and compare the activities of new and existing commercial and research photocatalytic materials. As a consequence, over the years a number of different tests for this purpose have been developed into ISO standards [5]. These tests include: the photo-oxidative bleaching of methylene blue $(\mathrm{MB})$ in aqueous solution, i.e. reaction (1), with organic $=\mathrm{MB},[6]$ and the photo-oxidation of $\mathrm{NO}_{x}$ gases [7]. However, it is worthwhile noting that these tests take a long time to run (3-5 hours) and require the use of expensive analytical equipment [5].

Recent work within the group has focused on the development of a rapid, simple method for assessing the activities of photocatalytic films, involving the use of a photocatalyst activity indicator ink (paii) [8-10]. The paii, when coated onto the photocatalyst film under test and irradiated with UV light, produces a striking colour change within a few minutes, at a rate which provides a measure of the activity of the underlying photocatalytic film [8-10]. The most used and effective of the paiis developed to date, contains the redox dye, Resazurin (Rz) which is blue, and readily and irreversibly reduced by the photogenerated electrons on the $\mathrm{TiO}_{2}$, to resorufin $(\mathrm{Rf})$, which is pink $[9,10]$. This reduction reaction is balanced by the concomitant rapid, irreversible reaction of the photogenerated holes with a sacrificial electron donor, glycerol, which is also present in the ink film. As a consequence, the overall photocatalytic process can be summarised as follows: 


$$
\text { Glycerol }+\mathrm{Rz} \longrightarrow \text { UV glyceraldehyde acid + Rf }
$$

Since both reactions (1) and (2) are semiconductor photocatalysed redox reactions, it might be expected that an effective photocatalyst for reaction (1) will also be effective for reaction (2), i.e. that the measured rates for the two very different processes will be related directly to one another. However, such a direct correlation cannot be assumed and needs to be demonstrated. Previous work established the existence of such a correlation in the rate of reduction of $\mathrm{Rz}$ in an $\mathrm{Rz}$ paii, via reaction (2) with that of oxidation of a thin solid organic film (stearic acid) via reaction (1), as mediated by a $\mathrm{TiO}_{2}$ photocatalytic film $[9,11]$. Clearly, more and different demonstrations of such direct correlations in rates are needed before it can be reasonably assumed that the Rz paii technology usually provides a quick route to assessing the activity of a photocatalyst towards the photo-oxidative mineralisation of organics. This short paper seeks to provide more of this evidence via a study of the correlation in rate of reaction (2) with that of reaction (1), where the organic is MB. Two schematic diagrams of the main electron transfer reactions associated with these two very different processes are illustrated in figure 1.

a.

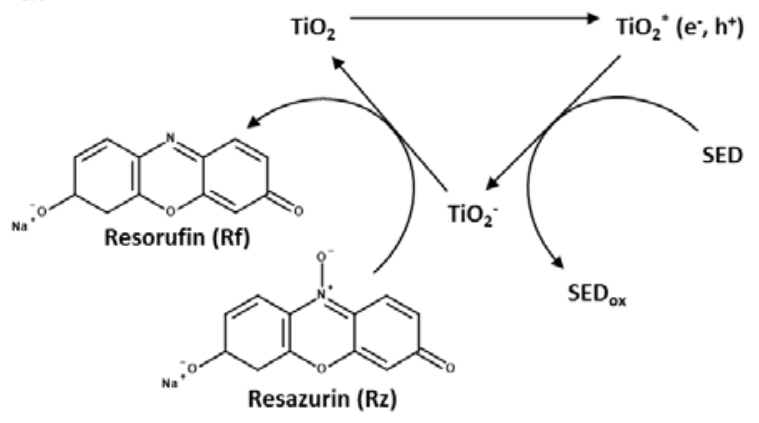

b.

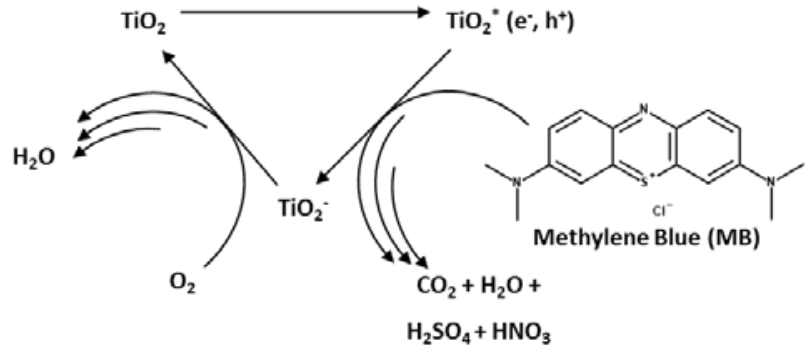

Figure 1 - Reaction scheme for the semiconductor photocatalyst driven processes: (a) reduction of resazurin to resorufin, and concomitant oxidation of a sacrificial electron donor (SED, usually glycerol) present and (b) the oxidative destruction of methylene blue to yield, eventually, $\mathrm{CO}_{2}, \mathrm{H}_{2} \mathrm{O}$ and mineral acids, by ambient oxygen. The many lines in the latter indicate that many electrons, the complete mineralisation of $\mathrm{MB}$ is a 102 electron process [12], need to be transferred to effect the mineralisation process, whereas the reduction of $\mathrm{Rz}$ is a $2 \mathrm{e}^{-}, 2 \mathrm{H}^{+}$process.

\section{Experimental}

Unless otherwise stated, all materials were purchased from Sigma Aldrich and used as received. All UV-vis spectra were recorded using an Agilent Technologies Cary $60 \mathrm{UV} / \mathrm{vis}$ Spectrophotometer. All irradiations were carried out using UVA light, from $2 \times 15 \mathrm{~W}$ broadband BLB tubes, with a principal wavelength of $352 \mathrm{~nm}$, and an irradiance of $2 \mathrm{~mW} \mathrm{~cm}^{-2}$. 


\subsection{Preparation of commercial self-cleaning glass samples with different activities}

The different activities of commercial self-cleaning glass samples, BioClean ${ }^{\mathrm{TM}}$ (manufacturer: Saint-Gobain) and Activ $^{\mathrm{TM}}$ (manufacturer: Pilkington), were both altered by heat treating the samples at $500^{\circ} \mathrm{C}$ in a furnace for different times. Previous work had established that at this temperature, the longer the heating time employed, the lower the activity of the thin $\mathrm{TiO}_{2}$ photocatalytic film, since the heat-treatment process promotes the diffusion of $\mathrm{Na}^{+}$ions from the underlying float glass, through the protective (usually $\mathrm{SiC}$ ) barrier layer, to the surface

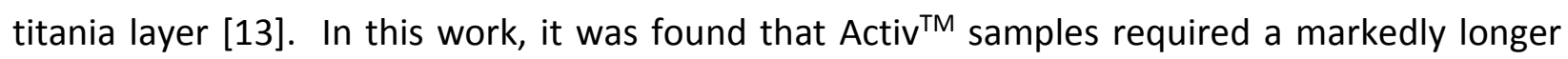
period of heat treatment (days vs. only hours for BioClean ${ }^{\mathrm{TM}}$ ) in order to achieve a significant loss in activity. Thus, typical heat treatment times used here were: 0, 6 and 24 hours for BioClean $^{\mathrm{TM}}$ and 0,5 and 20 days for Activ $^{\mathrm{TM}}$ samples, so as to produce a number of different glass samples exhibiting a wide range of activities, in which the $\mathrm{TiO}_{2}$ remains in its anatase form. As with most photocatalytic tests, it is very likely that the kinetics of photocatalysis will be a function of surface morphology, and as a consequence, it was important that in this work the samples tested were all similar in this respect, appearing under SEM analysis to have a cobblestone-like surface, with particles typically $30 \mathrm{~nm}$ in diameter [14]. Under SEM analysis, there was no change in the appearance of the film (ink or $\mathrm{TiO}_{2}$ ) after UV irradiation, details of the latter have been reported previously [14]. Another obvious route - not used here - to create $\mathrm{TiO}_{2}$ on glass samples of different activity but of similar morphology, is to alter the thickness of the $\mathrm{TiO}_{2}$ film, as this has been shown, for CVD films at least, to have a direct effect on the photocatalytic activity via the fraction of incident UV light absorbed by the film [15].

\subsection{Sol-Gel film preparation}

In order to ensure that the correlation was appropriate for both commercial (usually CVD produced) samples and lab-based, in this case sol-gel, titania films, a $\mathrm{TiO}_{2}$ sol-gel film was also tested in this study. The latter was prepared using a previously published method [16] in which briefly, $20 \mathrm{~mL}$ of titanium (IV) isopropoxide (Ti(OPri $\left.)_{4}\right)$ were added to a $100 \mathrm{~mL}$ round bottomed flask containing $4.65 \mathrm{~g}$ of glacial acetic acid using a syringe. The resulting $\mathrm{Ti}\left(\mathrm{OPr}^{\mathrm{i}}\right)_{4}$ solution was then transferred by syringe to a $250 \mathrm{~mL}$ conical flask containing $120 \mathrm{~mL}$ of distilled water and $1.08 \mathrm{~g}$ of concentrated nitric acid, and stirred at $80^{\circ} \mathrm{C}$ for $8 \mathrm{~h}$, before being filtered through a $0.45 \mu \mathrm{m}$ syringe filter to remove any aggregated oxide. The filtrate was then transferred to an acid digestion bomb and heated at $220^{\circ} \mathrm{C}$ for $12 \mathrm{~h}$. After cooling, the resulting paste was subjected to ultrasound to disperse the particles, and then concentrated, via rotary evaporation, to form a thick white paste with a $10 \% \mathrm{wt}$. loading of $\mathrm{TiO}_{2}$. Polyethylene glycol (PEG), $5 \mathrm{wt} \%$, was mixed into the paste to provide greater stability and the product was then stored at $\sim 5^{\circ} \mathrm{C}$. The final sol-gel film was prepared by diluting the paste by 100 fold using ethanol as the diluent, to produce a much less viscous solution that was then applied to a microscope slide using a doctor blade technique to create the $\mathrm{TiO}_{2}$ sol-gel film. In the latter case, two parallel lines of adhesive tape, $2 \mathrm{~cm}$ apart were laid down onto the slide and the 
diluted sol-gel paste drawn down between them, so as to generate a $48 \mu \mathrm{m}$ wet film of the solgel. This film was then annealed at $450^{\circ} \mathrm{C}$ for 30 minutes to yield a robust, clear film of titania, measured to be ca. $200 \pm 20 \mathrm{~nm}$ thick using SEM. The annealed $\mathrm{TiO}_{2}$ films are in their anatase crystal form [16].

\subsection{Reduction of resazurin paii}

The preparation of the resazurin paii is described in detail elsewhere [17]. Briefly, $10 \mathrm{mg}$ of resazurin sodium salt and $1 \mathrm{~g}$ of glycerol were added to $10 \mathrm{~mL}$ of a 1.5 wt.\% solution of hydroxyethyl cellulose. The solution was stirred overnight to ensure complete dissolution of the dye. When not in use, the ink was stored in the fridge, and was stirred for 10 minutes prior to use. The Rz paii was applied using the draw-down method, with a K-bar \#3 (delivering a 24 $\mu \mathrm{m}$ wet film thickness), which was dried in air for at least $20 \mathrm{~min}$ before use. The dried $\mathrm{Rz}$ ink film was ca. $2.1 \mu \mathrm{m}$ thick, as measured using the Swanepoel method [18]. 


\section{Results}

\subsection{The MB test}

A modified version of the MB ISO, i.e. ISO10678:2010 [6], was used to quantify the activities of the different titania-based photocatalyst films on glass, in which one wall of a $1 \mathrm{~cm}$ plastic cuvette was replaced with the sample under test, as illustrated in figure2(a). The photocatalytic sample under test was affixed to the cell using a silicone sealant (Wacker Silicones Elastosil A07 translucent silicone sealant) deposited around the outside of the cuvette. In a typical run, $3 \mathrm{~mL}$ of a $5 \mu \mathrm{M}$ methylene blue aqueous solution were added to the reaction vessel, followed by a crown stirrer, which was spun continuously at 800 RPM to ensure that the MB solution remained aerated throughout the irradiation.

a.

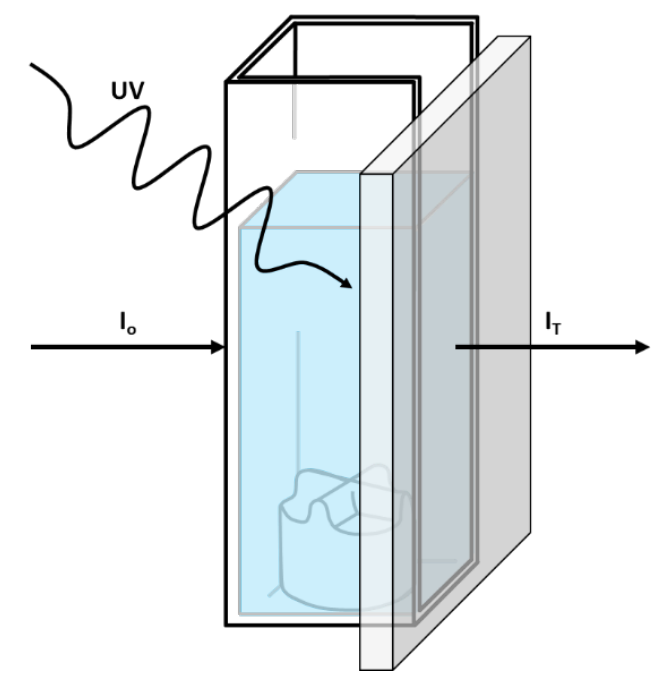

b.

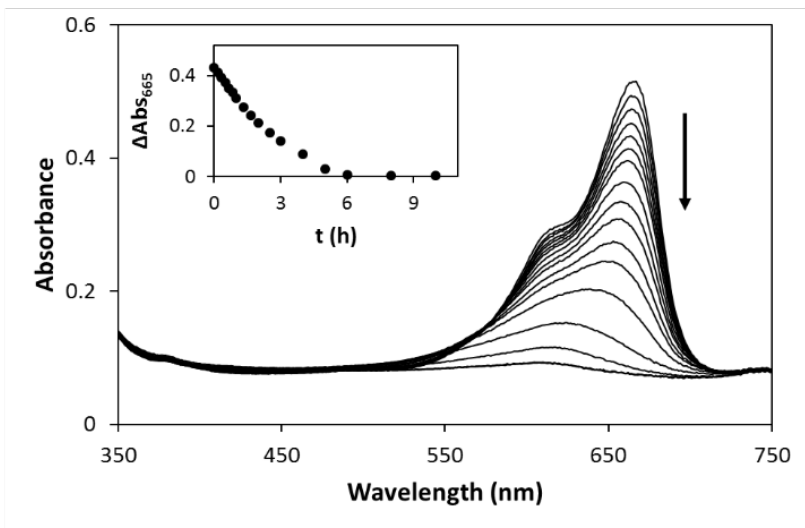

Figure 2 - (a.) Schematic illustration of the reaction setup for the modified BS ISO 10678:2010 MB photocatalysed oxidation test. The sample under test was affixed to a three-walled cuvette, and irradiated through the MB solution and the UV/Vis spectra of the solution monitored as a function of irradiation time and (b) a typical set of UV-vis spectra recorded using the system illustrated in (a) for a non-heat-treated sample of Activ ${ }^{\mathrm{TM}}$, with the inset diagram showing the absorbance decay profile at 665 $\mathrm{nm}$ (taken from the main diagram) vs irradiation time, $t$.

The system was then irradiated with UV light $\left(2 \mathrm{~mW} \mathrm{~cm}^{-2}\right)$ and the UV/Vis absorption spectrum of the MB solution recorded as a function of irradiation time. The results of this work for a typical (non-heat-treated) sample of commercial self-cleaning Glass (Activ ${ }^{\mathrm{TM}}$ ) are illustrated in figure 2(b), along with an insert plot of the decay in the absorbance, at $665 \mathrm{~nm}$, due to $M B$, which yielded a value for the initial rate, $r_{i}(M B)$, for reaction (1), where the organic $=M B$.

\subsection{The Rz test}

Each photocatalytic film tested using the $M B$ test, was then coated with the $\mathrm{Rz}$ ink and irradiated (irradiance $=2 \mathrm{~mW} \mathrm{~cm}^{-2}$ ) with UV light and the change in the UV/Vis absorbance 
spectrum of the Rz film monitored as a function of irradiation time. A schematic of the reaction setup is illustrated in figure 3(a). The UV/Vis spectrophotometry results generated using this system, for a typical (non-heat-treated) piece of commercial self-cleaning Glass (Activ ${ }^{\mathrm{TM}}$ ) are illustrated in figure 3(b), along with an insert plot of the decay in the absorbance, at $608 \mathrm{~nm}$, due to the photocatalysed reduction of $\mathrm{Rz}$, which yielded a value for the initial rate, $r_{i}(R z)$, for reaction (2).

a.

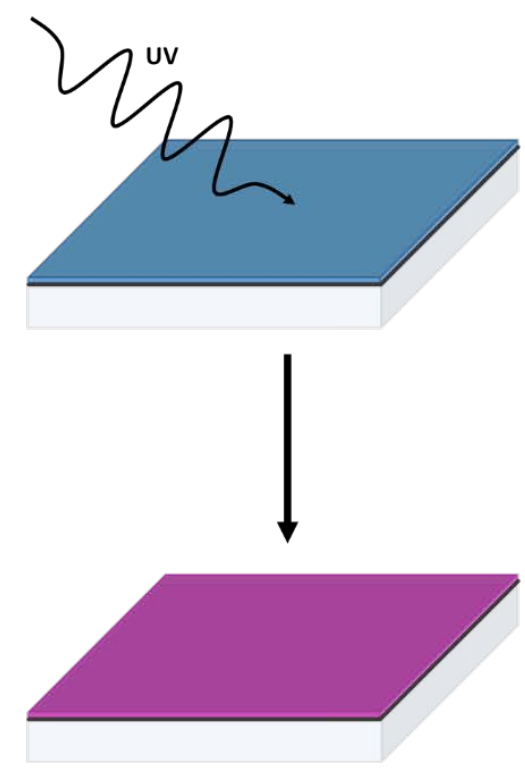

b.

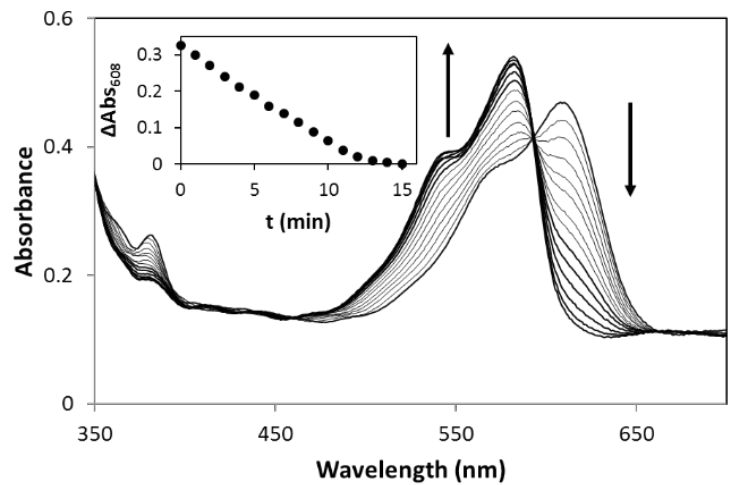

Figure 3 - (a.) Schematic illustration of the Rz Paii ink irradiation system, in which an Rz ink covered sample turns from blue to pink upon UV irradiation and (b.) a typical set of UV/Vis spectral changes for a non-heat-treated sample of Activ $^{\mathrm{TM}}$, arising from the Rz ink test, with the inset diagram showing the decay profile at $608 \mathrm{~nm}$ vs irradiation time, $t$, from which a value for the initial rate, $r_{i}(R z)$ for reaction (2) could be gleaned.

An analysis of the decays in the insert diagrams in figures 2(b) and 3(b), reveals that the photocatalysed oxidation of the MB is first order, whereas that of Rz reduction in the Rz paii is zero order, as has been noted previously $[6,10,12,18]$.

\subsection{MB oxidation vs $\mathrm{Rz}$ reduction}

The $M B$ and $R z$ tests described above were used to determine the initial rates of $M B$ oxidation, $r_{i}(M B)$ (units: absorbance units $\mathrm{h}^{-1}$ ), and $\mathrm{Rz}$ reduction, $r_{i}(R z)$, (units: absorbance units $\min ^{-1}$ ), for 3 differently-heated samples of BioClean ${ }^{\mathrm{TM}}$ and 3 differently-heated samples of Activ ${ }^{\mathrm{TM}}$, and the lab-made $\mathrm{TiO}_{2}$ sol-gel film, all of which exhibited different photocatalytic activities. Each pair of $r_{i}(M B)$ and $r_{i}(R z)$ values for each sample tested were then plotted against each other, i.e. $r_{i}(M B)$ vs. $r_{i}(R z)$ and the results of this work are illustrated in figure 4. The latter is a good straight line, which suggests that for thin film of titania, on glass at least, the rate of MB photo-oxidation in solution, via reaction (1), is linearly correlated with that of $\mathrm{Rz}$ dye reduction in a paii, via 
reaction (2). The significant difference between the two processes is that the former is slow whereas the latter is fast. For example, for a typical piece of Activ ${ }^{\mathrm{TM}}$ self-cleaning glass, reaction (1) (with organic $=\mathrm{MB}$ ) takes about $5 \mathrm{~h}$ whereas reaction (2) takes $12 \mathrm{~min}$, see figures 2 (b) and 3(b).

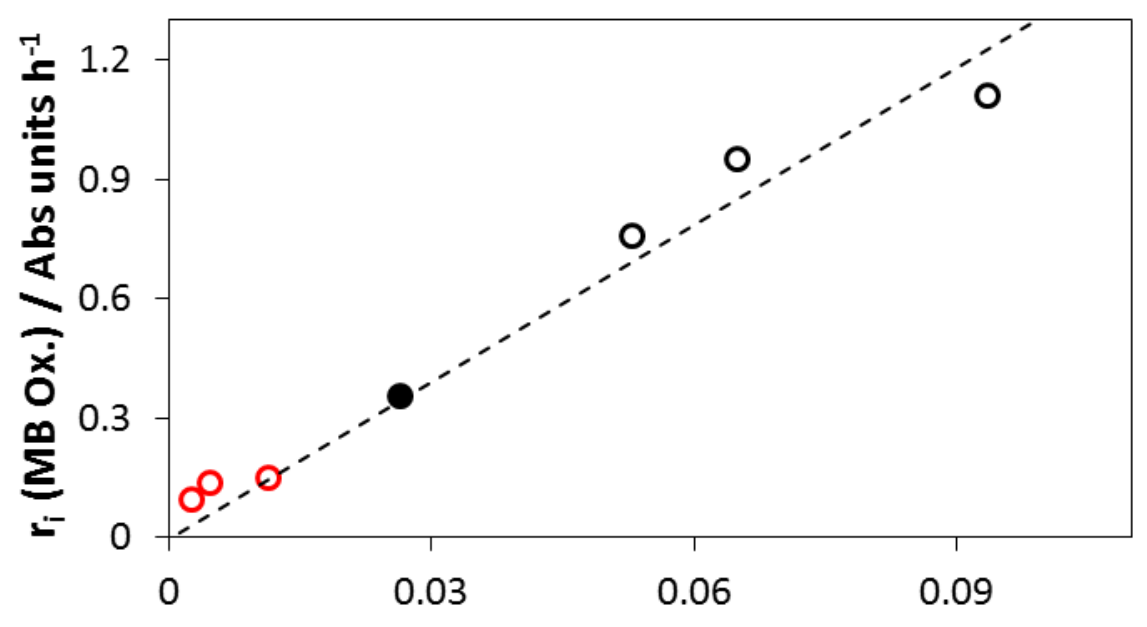

$r_{i}$ (Rz Red.) / Abs units min $^{-1}$

Figure 4 - Plot of the measured initial rate of $M B$ oxidation, $r_{i}(M B)$, vs the initial rate of $\mathrm{Rz}$ reduction, $r_{i}(R z)$, for samples of BioClean ${ }^{\mathrm{TM}}$ (red empty circles), Activ ${ }^{\mathrm{TM}}$ (black empty circles) of different activity and a lab-made $\mathrm{TiO}_{2}$ sol-gel film (full black circle).

\section{Conclusions}

The initial rate of the photocatalysed oxidation of methylene blue by dissolved oxygen in solution, $r_{i}(M B)$, correlates linearly with the rate of reduction of resazurin in a Paii, $r_{i}(R z)$. This correlation provides further support for the contention that, when comparing photocatalytic materials of similar physical form, such as self-cleaning glass samples as used here, the Rz paii provides a simple and quick method for assessing photocatalytic activity for the much slower oxidative mineralisation of organics, such as MB. The fact that other work shows that the Rz paii technology can be used to assess the activities of photocatalytic films in situ, using only a simple mobile phone and a RGB colour analysis app, both of which are very inexpensive and simple to use, adds to the attraction of the paii technology as a quick method for testing such materials [19]. 


\section{References}

[1] P. Pichat, Photocatalysis and water purification from fundamentals to recent applications, 1st edn, Wiley-VCH, Germany, 2013.

[2] A. Mills, S. Lee, A web-based overview of semiconductor photochemistry-based current commercial applications, J Photochem. Photobiol. A: Chem. 152 (2002) 233-247.

[3] A. Mills, C. O'Rourke, K. Moore, Powder semiconductor photocatalysis in aqueous solution: an overview of kinetics-based reaction mechanisms, J. Photochem. Photobiol. A: Chem. 310 (2015) 66-105.

[4] Y. Ohko, Y. Nakamura, N. Negishi, S. Matsuzawa, K. Takeuchi, Photocatalytic oxidation of nitrogen monoxide using TiO2 thin films under continuous UV light illumination, J. Photochem. Photobiol. A: Chem. 205 (2009) 28-33.

[5] A. Mills, C. Hill, P.K.J. Robertson, Overview of the current ISO tests for photocatalytic materials, J. Photochem. Photobiol. A: Chem. 237 (2012) 7-23.

[6] ISO 10678. Fine ceramics (advanced ceramics, advanced technical ceramics) -Determination of photocatalytic activity of surfaces in an aqueous medium by degradation of methylene blue, ISO, Geneva, 2010

[7] ISO 22197-1. Fine ceramics (advanced ceramics, advanced technical ceramics) -- Test method for air-purification performance of semiconducting photocatalytic materials -- Part 1: Removal of nitric oxide, ISO, Geneva, 2007.

[8] A. Mills, N. Wells, Reductive photocatalysis and smart inks, Chem. Soc. Rev. 44 (2015) 28492864.

[9] A. Mills, J. Wang, S.K. Lee, M. Simonsen, An intelligence ink for photocatalytic films, Chem. Commun. 21 (2005) 2721-2723.

[10] A. Mills, J. Wang, M. McGrady, Method of rapid assessment of photocatalytic activities of self-cleaning films, J. Phys. Chem. B 110 (2006) 18324-18331.

[11] A. Mills, N. Wells, C. O'Rourke, Correlation between $\triangle A b s, \triangle R G B$ (red) and stearic acid destruction rates using commercial self-cleaning glass as the photocatalyst, Catalysis Today 230 (2014) 245-249.

[12] A. Mills, An overview of the methylene blue ISO test for assessing the activities of photocatalytic films, Appld. Catal. B: Environmental 128 (2012) 144-149. 
[13] A. Mills, C. O'Rourke, N. Wells, A smart ink for the assessment of low activity photocatalytic surfaces, Analyst 139 (2014) 5409-5414.

[14] A. Mills, A. Lepre, N. Elliott, S. Bhopal, I.P. Parkin, S.A. O'Neill, Characterisation of the photocatalyst Pilkington Activ $^{\mathrm{TM}}$ : a reference film photocatalyst? J. Photochem. Photobiol. A: Chem. 160 (2003) 213-224.

[15] A. Mills, S. Lee, A. Lepre, I. P. Parkin and S. A. O'Neill, Spectral and photocatalytic characteristics of $\mathrm{TiO}_{2}$ CVD films on quartz, Photochem. Photobiol, Sci, 2002, 1865-868.

[16] A. Mills, N. Elliott, G. Hill, D. Fallis, J. R. Durrant, R. L. Willis, Preparation and Characterisation of novel thick sol-gel titania film photocatalysts, Photochem. Photobiol. Sci. 2 (2003) 591-596.

[17] A. Mills, J. Hepburn, D. Hazafy, C. O'Rourke, J. Krysa, M. Baudys, M. Zlamal, H. Bartkova, C.E. Hill, K.R. Winn, M.E. Simonsen, E.G. Søgaard, S.C. Pillai, N.S. Leyland, R. Fagan, F. Neumann, C. Lampe, T. Graumann, A Simple, Inexpensive method for the rapid testing of the photocatalytic activity of self-cleaning surfaces, J. Photochem. Photobiol. A: Chem. 272 (2013) 18-20.

[18] A. Mills, N. Wells, J. MacKenzie, G. MacDonald, Kinetics of reduction of a resazurin-based photocatalytic activity ink, Catalysis Today, accepted for publication dx.doi.org?10.1016/jcattd.2016.05045.

[19] A. Mills and N. Wells, Indoor and outdoor monitoring of photocatalytic activity using a mobile phone app. and a photocatalytic activity indicator ink (paii), J. Photochem. Photobiol. A, 2015, 298, 64-67. 